\title{
Dealing with a clinically important anti-M case with cross-reactivity induced by monoclonal typing reagent
}

Ehsan Shahverdi ${ }^{1}$, Mostafa Moghaddam ${ }^{2}$, Hoda Sheibani ${ }^{2}$, Shadi Voghoufi ${ }^{2}$

${ }^{1}$ MD, Department of Cardiology and Angiology, Bonifatius Academic Teaching Hospital Lingen, Westphalian Wilhelms University of Münster, Lingen, Germany

${ }^{2}$ MSc. CLS (ASCP) BB, Blood Transfusion Research Center, High Institute for Research and Education in Transfusion Medicine, Tehran, Iran

Type of article: Case report

\begin{abstract}
Introduction: The naturally occurring "Anti-M" antibody, which is usually active at temperatures below $37^{\circ} \mathrm{C}$ and has no clinical significance, can lead to discrepancy in $\mathrm{ABO}$ blood grouping and confusion in diagnosis.

Case Presentation: This paper reports the case of a 28 -year-old woman whose unanticipated reaction in her reverse blood grouping was observed due to the presence of anti-M, which made interpretation of her blood group difficult. The reason for this discrepancy created an interesting case to analyze.

Take-away Lesson: A laboratory should always choose the reagent that is most suitable to the profiles of patients referred to that laboratory. It should be noted that if an anti-M is found in an $\mathrm{M}+$ patient with negative autocontrol, it is not correct to conclude that there is a "partial M".

Keywords: ABO discrepancy, Anti-M, He antigen, Monoclonal antibodies
\end{abstract}

Abbreviations / Acronyms:

DAT: Direct Antiglobulin Test; GPA: Glycophorin A; GPB: Glycophorin B; HDFN: Hemolytic Disease of Fetus and Newborn; IBTO: Iranian Blood Transfusion Organization

\section{Introduction}

The MNS is one of the most highly complex immune blood group systems whose recombination between closely linked homologous genes contributes to its complexity as Rh system $(1,2)$. The MNS system is composed of 49 antigens, which are encoded by one or both of glycophorin A and glycophorin B and carried by them. These glycoproteins may also act as cytokines and/or pathogens receptors for pathogens such as Malaria parasite and Plasmodium falciparum (3). Twenty two percent of Caucasians and $26 \%$ of blacks lack the M antigen and therefore are able to produce anti-M when exposed to the antigen (4). Shahverdi, et al. have reported that $14 \%$ of the Iranian general population lack $\mathrm{M}$ antigen (5). As a low-prevalence antigen, He, (previously known as Henshaw) among a series of antigens related to MNS blood group system was first described in 1951(4, 6). It was found that the $\mathrm{He}^{\mathrm{s}}+$ phenotype was seen only when S or s was expressed (7). The naturally occurring "Anti-M" antibody, which is usually active at temperatures below $37^{\circ} \mathrm{C}$ and has no clinical significance, can lead to discrepancy in ABO blood grouping and confusion in diagnosis (6). Many examples of anti-M and anti-N are cold reactive, non-red stimulated antibodies thus of no clinical significance. Both IgM and IgG anti-M and anti-N are reported. Some cases have reported that both antibodies have caused transfusion reactions and hemolytic disease of fetus and newborn (HDFN) $(7,8)$. Anti-M in the presence of hypothermic therapies or surgical procedures could also contribute to hemolysis (9). If anti-M antibodies are found to be active at $37^{\circ} \mathrm{C}$ antigens, negative or red cells that are compatible by an indirect antiglobulin test (IAT) should be provided. The first example of the anti-He was present in a serum containing anti-M and since then a number of monoclonal antibody reagents have been identified as carrying anti-

\section{Corresponding author:}

Dr. Mostafa Moghaddam. Blood Transfusion Research Center, High Institute for Research and Education in Transfusion Medicine, Tehran, Iran. Tel: 0098-21-82052212, Fax: 0098-21-88628741,

E-mail: m.moghaddam@ibto.ir and mostafamoghaddam58@gmail.com

Received: December 24, 2019, Accepted: September 15, 2020, Published: December 2020

iThenticate screening: October 18, 2020, English editing: December 2020, Quality control: December 04, 2020

(C) 2020 The Authors. This is an open access article under the terms of the Creative Commons Attribution-NonCommercialNoDerivs License, which permits use and distribution in any medium, provided the original work is properly cited, the use is non-commercial and no modifications or adaptations are made. 
He in them $(4,6)$. This phenomenon can create cross reactivity problems between closely related antigens specificity but not identical.

\section{Case presentation}

\subsection{Clinical presentation and history}

This is the case of a 28-year-old woman who was hospitalized for her second delivery with hemoglobin $7.0 \mathrm{~g} / \mathrm{dl}$ at presentation with no history of blood transfusions. An unanticipated reaction and discrepancy in her ABO reverse blood grouping was observed due to the presence of anti-M, which led to unexpected cross-reactivity between anti$\mathrm{M}$ monoclonal typing reagent and possible presence of a rare low frequency RBCs He antigen.

\subsection{Laboratory findings}

The patient's EDTA blood sample was received by the Immunohematology Reference Laboratory as a case of blood group discrepancy for further investigation. At first, $\mathrm{ABO}$ and $\mathrm{Rh}$ (D) typing were carried out both in tube and microplate technique (Qwalys 3, Diagast, France). Although ABO forward grouping was found to be A positive, an agglutination with A1 Cell was revealed in reverse (plasma) grouping (Figure 1). Antibody screening test was performed in Low Ionic Strength Solution (LISS) with both gel technique (MTC Invitro Diagnostics AG, Germany) and typical test tube method. Moreover, her plasma was evaluated against commercially accessible 3-cell panel (IBTO, 16IP3C.107). Positive reaction with panel cell I and III was observed in the results, while the reaction was found to be negative with panel cell II (Figure 2). Furthermore, 11-cell ID panel (IBTO, 6IP11C.107.1) was applied for antibody identification. Identified antibody was subsequently confirmed by selected cells antibody panel (IBTO, 16 IBTO/SELD2). Thereafter, the patient's complete phenotype was determined with tube method. All positive (heterozygous) and negative control cells reacted as expected. The patient's plasma was tested with Papain enzymetreated RBCs as further confirmation of Anti-M. Direct antiglobulin test and auto control test were performed using tube technique.

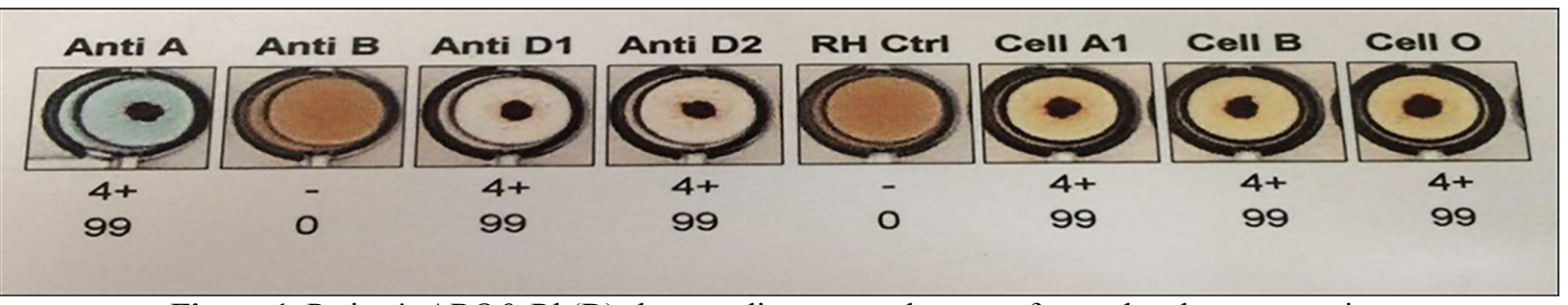

Figure 1. Patient's ABO\& Rh(D) shows a discrepancy between forward and reverse typing

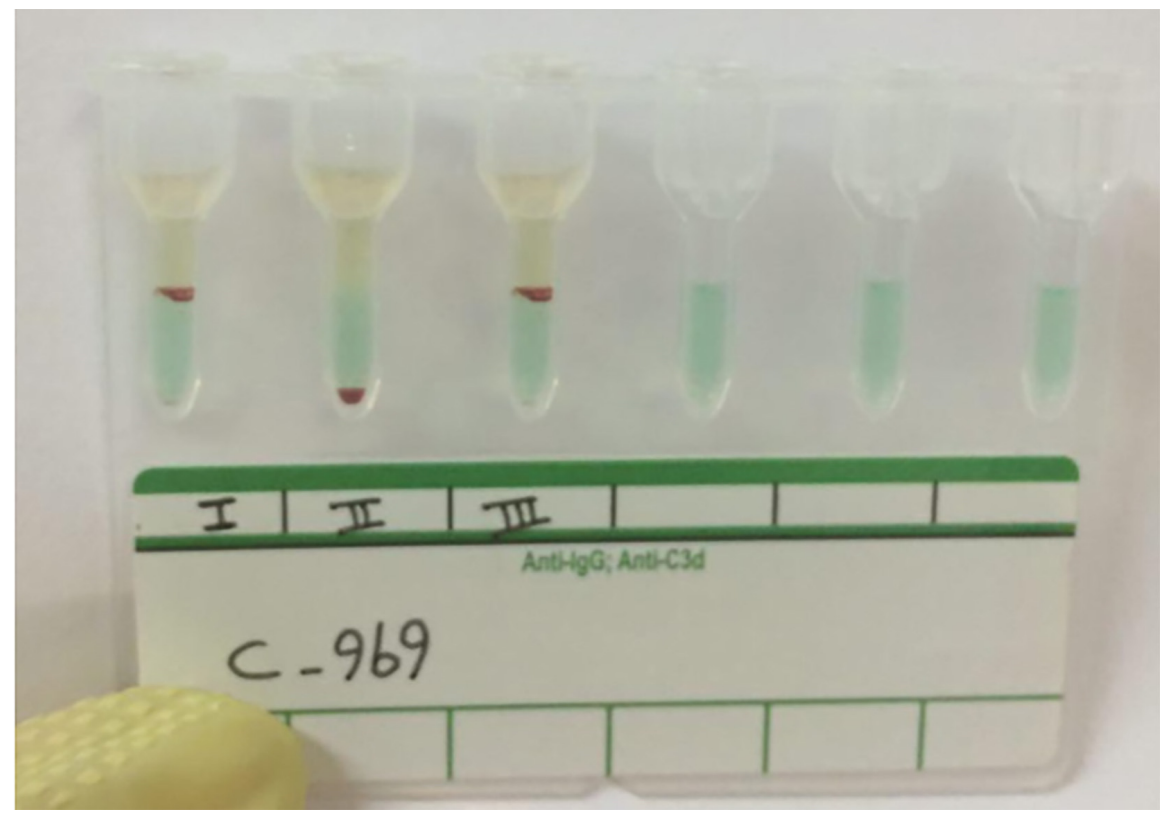

Figure 2. Antibody screening test with 3 cell panel 


\section{Discussion}

According to the results of this study, the patient's antibody was identified and confirmed as Anti-M. Strong 4+ reaction was observed with both $\mathrm{M}+\mathrm{N}$ - homozygous cells and with $\mathrm{M}+\mathrm{N}+$ heterozygous cells in the panel, while no antibody reactions were seen with enzyme treated cells. In addition, the patient's direct antiglobulin test (DAT) and autocontrol were found to be negative. $\mathrm{M}$ and $\mathrm{N}$ typing were performed to confirm the nature of the patient's antibody and whether it was auto or allo immune, and surprisingly, her $\mathrm{M}$ antigen was positive (Table1). Interestingly, the patient's RBCs were evaluated with two different sources of M-antisera reagents from different companies [(Immundignostika, LOT: OMM113, Clone NO:M-11H2) and (SIFIN, LOT: G40710, Clone NO:M$11 \mathrm{H} 2)$ ) and reacted positively with both, while the third antisera (LORNE, LOT:31160A) was quite negative. Notably, both positively reacted antisera had the same number of clones, and negative antisera was shown to be polyclonal. The anti-M titers was found to be 64 with $\mathrm{M}+\mathrm{N}-$ homozygous cell, while it was 16 with $\mathrm{M}+\mathrm{N}+$ heterozygous cell at AHG phase, according to the manufacturers' directions.

For final consideration due to the presence of anti-M antibody in the patient's plasma, a blood sample was taken from her husband, and his RBC phenotypes showed that he was M, N and S-antigen positive. Cross match between patient plasma and her husband's RBCs was incompatible. As it is reminded in the monoclonal typing reagent insert accompanying the anti-M anti-sera, unexpected results may occur from very rare types of antigens. This warning was noted in one of the anti-M reagents we used (10). Some common monoclonal anti-M clones (e.g.2514E6 and M-11H2) extensively cross-react with the low prevalence He antigen (Henshaw, MNS6) (11). Most anti-M reagents detect as well as He (Henschaw) which generally is found in 2.3 percent of the central African population (10). It is produced by DNA exchanging between the glycophorin A (GPA) and glycophorin B (GPB) genes, which are located close together on chromosome 4. The generated hybrid glycoproteins possess novel He antigen in MNS system (3). Although the full details of monoclonal antibody typing reactants need not be mentioned, following the instructions is essential for using these typing reagents, as they are produced specifically for a known epitope compare to using human-source reagents.

Table 1. Patient's RBC phenotype

\begin{tabular}{|c|c|c|c|c|c|c|c|c|c|c|c|c|c|c|}
\hline $\mathbf{D}$ & $\mathbf{C}$ & $\mathbf{E}$ & $\mathbf{c}$ & $\mathbf{e}$ & $\mathbf{K}$ & $\mathbf{k}$ & $\mathbf{F y}^{\mathbf{a}}$ & $\mathbf{F y}^{\mathbf{b}}$ & $\mathbf{J k}^{\mathbf{a}}$ & $\mathbf{J k}^{\mathbf{b}}$ & $\mathbf{M}$ & $\mathbf{N}$ & $\mathbf{S}$ & $\mathbf{S}$ \\
\hline+ & + & + & + & + & $\mathbf{0}$ & + & $\mathbf{0}$ & + & + & + & + & + & + & + \\
\hline
\end{tabular}

Both commercially accessible monoclonal antibodies used to phenotype our patient had one source clone type. This clone was found to be reacted against $\mathrm{M}$ antigen related epitope of GPA, and cross-react to rare variant erythrocytes carrying GPA of He (11) type, therefore can lead to cause false M+ phenotype. Cross-reactivity between antigens take place when an antibody raised against one particular antigen successfully binds with another, different antigen, leading to potentially false positive results.

\section{Conclusions}

A laboratory should always select and use the reagent that is most appropriate to the characteristics of the patient population referred to that laboratory. It should be noted that if an anti-M is found in a $\mathrm{M}+$ patient with negative autocontrol, it is not correct to conclude that the patient has a "partial M" antigen. This has not been reported in the past. Polyclonal anti-M does not show cross -reactivity. One should be aware that possible cross-reactivity might occur in serological parentage testing. Molecular genotyping tests will be needed to confirm the patient's M-N + and $\mathrm{He}+$ blood type.

\section{Conflict of Interest:}

There is no conflict of interest to be declared.

Authors' contributions:

All authors contributed to this project and article equally. All authors read and approved the final manuscript.

\section{References:}

1) Fung MK. Other blood group systems and antigens. American Association of Blood Banks. Technical manual, Fung MK, Grossman BJ, Hillyer CD, and Westhoff CM. Bethesda: American Association of Blood Banks. 2014: 337-66. 
2) Schoeman EM, Roulis EV, Perry MA, Flower RL, Hyland CA. Comprehensive blood group antigen profile predictions for Western Desert Indigenous Australians from whole exome sequence data. Transfusion. 2019 Feb;59(2):768-78. DOI: 10.1111/trf.15047, PMid: 30520525

3) Dean L. Blood groups and red cell antigens. National Center for Biotechnology Information; 2005.

4) Reid ME, Lomas-Francis C, Olsson ML. The blood group antigen factsbook. Academic press; 2012 Nov 7.

5) Shahverdi E, Moghaddam M, Talebian A, Abolghasemi H. Distribution of blood groups in the Iranian general population. Journal of Blood Group Serology and Molecular Genetics Volume 32, Number 4, 2016. 2016 Dec;32(4):135. PMID: 28257227

6) Mitra R, Mishra N, Rath GP. Blood groups systems. Indian J Anaesth. 2014 Sep;58(5):524. doi: 10.4103/0019-5049.144645, PMid: 25535412, PMCid: PMC4260296

7) Issitt PD, Anstee DJ. Applied blood group serology. Durham, NC: Montgomery Scientific Publications; 1998 Jan.

8) Yasuda H, Ohto H, Nollet KE, Kawabata K, Saito S, Yagi Y, Negishi Y, Ishida A. Hemolytic disease of the fetus and newborn with late-onset anemia due to anti-M: a case report and review of the Japanese literature. Transfus Med Rev. 2014 Jan 1;28(1):1-6. PMID: 24262303, doi: 10.1016/j.tmrv.2013.10.002

9) Poole J, Daniels G. Blood group antibodies and their significance in transfusion medicine. Transfus Med Rev. 2007 Jan 1;21(1):58-71. PMID: 17174221, doi: 10.1016/j.tmrv.2006.08.003

10) Makroo RN, Rajput S, Agarwal S, Chowdhry M, Prakash B, Karna P. Prevalence of irregular red cell antibody in healthy blood donors attending a tertiary care hospital in North India. Asian J Transfus Sci. 2018 Jan;12(1):17. doi: 10.4103/ajts.AJTS_4_17, PMid: 29563670, PMCid: PMC5850692

11) Jaskiewicz E, Jodłowska M, Kaczmarek R, Zerka A. Erythrocyte glycophorins as receptors for Plasmodium merozoites. Parasites \& vectors. 2019 Dec;12(1):317. DOI: 10.1186/s13071-019-3575-8, PMid: 31234897, PMCid: PMC6591965 